\title{
A simple lysimeter for soil water sampling in south Florida 1
}

Kati W. Migliaccio, Yuncong Li, Harry Trafford, and Edward Evans ${ }^{2}$

\section{Introduction}

With growing public concerns regarding water quality, researchers are diligently developing management practices that will reduce agrochemical leaching. Hence, identification of agrochemicals in leachate assists in assessing the effectiveness of management practices. One device researchers often use to estimate leachate properties is the lysimeter. Lysimeters are devices used to collect soil water in order to measure chemical characteristics of water which has leached through the soil profile.

Lysimeters may be purchased from several providers; however, they are generally expensive and may not be practical for unusual soil types such as Krome soil and unusual research objectives such as capturing total leachate volumes.

South Floridian Krome soil is very gravelly and shallow in depth, with low organic matter and a high infiltration rate $(\mathrm{Li}, 2001)$. Hence, soil and water research on this soil is often associated with soil properties relative to water quality.

\section{Lysimeter Design}

Infiltration characteristics, which are predominantly influenced by soil properties, were considered in the lysimeter design. Lysimeters were designed to capture the large rainfalls common during south Florida's rainy season with consideration to the rapid infiltration rate of Krome soil. The original design was improved for collecting soil leachate in soil ammendment experiments (Li et al., 2002; Wang et al., 2005).

A modification to this design was constructed to provide a stronger collection surface and more efficient connections for sample collection. The design includes the following materials: 5-gallon bucket, bucket lid, fittings for flexible tubing, flexible tubing, collection plate, mesh filter, and acid-washed silica sand (Figures 1, 2, and 3). The flexible tubing provides access to the inside of the lysimeter once it is buried. The collection plate is attached to the bucket lid. A hole is then drilled through the collection plate and lid to provide for collected water to be funneled into the bucket. A mesh filter (a non-reactive fiberglass screen) is glued over the drilled hole to prevent debris (soil, rocks, etc.) from

1. This document is ABE 361, from the Department of Agricultural and Biological Engineering, Florida Cooperative Extension Service, Institute of Food and Agricultural Sciences, University of Florida. First published March 2006. Please visit the EDIS Web site at http://edis.ifas.ufl.edu

2. Kati W. Migliaccio is Assistant Professor, Tropical Research and Education Center (TREC), Homestead, FL; Yuncong Li is Associate Professor, TREC, Homestead, FL; Harry Trafford is Laboratory Technician, TREC, Homestead, FL; Edward Evans is Assistant Professor, TREC, Homestead, FL 
entering the bucket. Over the mesh, acid-washed silica sand (coarse $6 / 20$ grit) is layered to further prevent entry and clogging of the hole. The silica sand is acid-washed and rinsed to prevent the sand from chemically influencing the collected water.

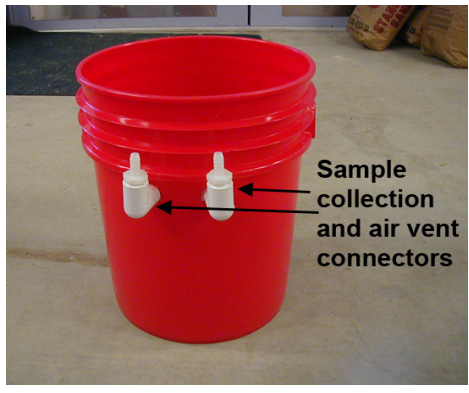

Figure 1.a Credits: Kati W. Migliaccio (c) UF/IFAS 2006

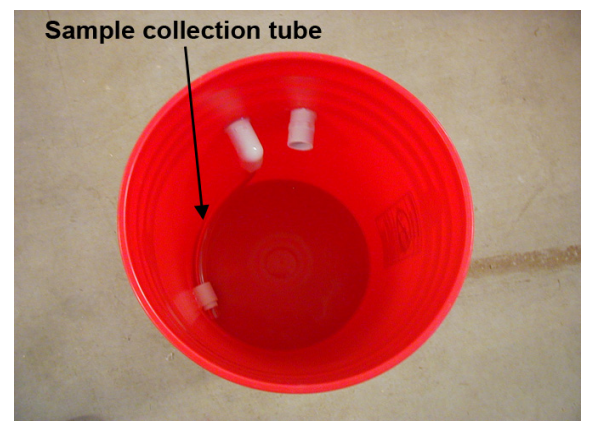

Figure 1.b Credits: Kati W. Migliaccio (c) UF/IFAS 2006

Figure 1. Lysimeters without lid, side view and top view

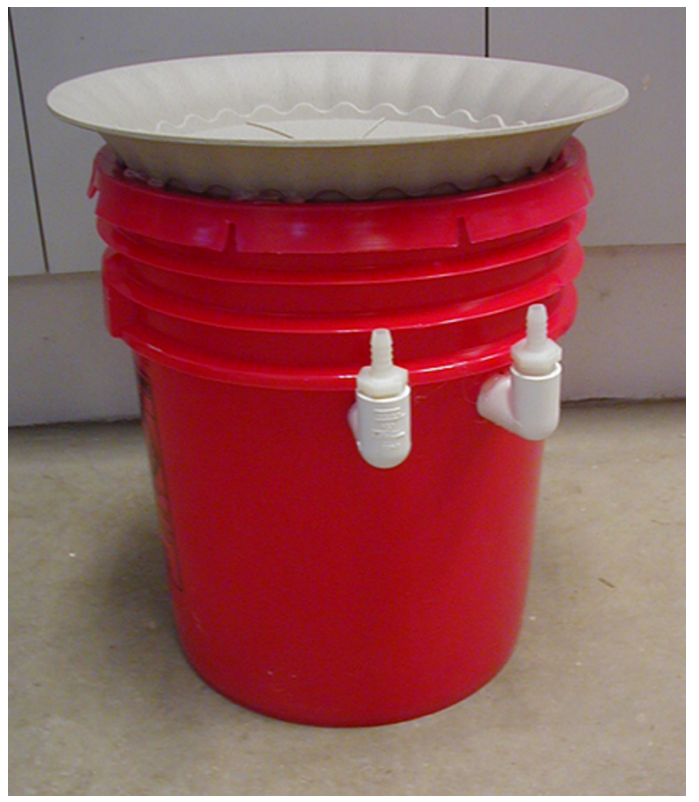

Figure 2.a Credits: Kati W. Migliaccio (c) UF/IFAS 2006

The lysimeters are installed by digging cylindrical holes into the limestone bedrock to a depth so that the top of the lysimeter is below crop

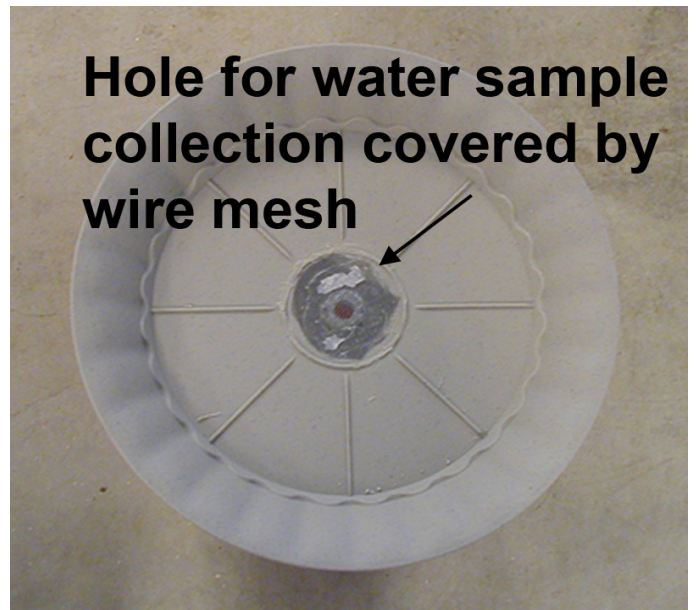

Figure 2.b Credits: Kati W. Migliaccio (c) UF/IFAS 2006

Figure 2. Lysimeter with stronger collection plate, side view and top view

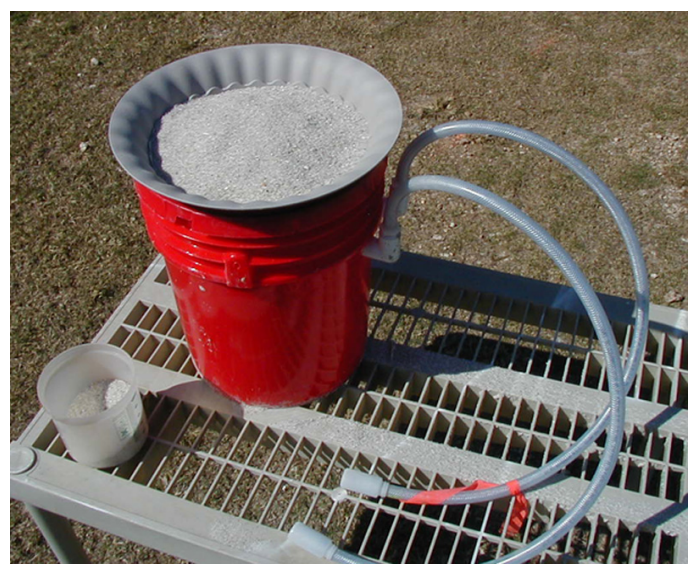

Figure 3. Lysimeter with sand placed in collecting plate and flexible tubing attached for sample collection Credits: Harry Trafford (c) UF/IFAS 2006

roots. When installing the lysimeter, the two flexible tubes are left protruding from the ground. Water collected in the lysimeter is removed using the two tubes: one tube serves as an air vent while the other is connected to a peristaltic pump.

During the life of the lysimeter project, it is important to pump the lysimeters frequently. The frequency of pumping will depend on the infiltration and rainfall characteristics at the installed location. Lysimeters should be pumped at a frequency to prevent overflowing. If a lysimeter overflows, sample integrity could be compromised.

\section{Advantages:}


- Easy to assemble

- Requires minimum maintenance once installed

- Total cost is relatively low (\$12 US dollars 2006 price)

\section{Limits:}

- Manual pumping is required

- Lysimeters must be checked on a regular schedule and pumped when full (depending on rain frequency and intensity this can be quite often)

\section{Conclusion}

The lysimeter design presented provides an alternative method for collecting agrochemical leachate. These devices can be used to compare Best Management Practices, identify and quantify potential pollutant sources, and gain a better understanding of the infiltration properties of a particular soil type.

\section{References}

Li, Y.C. 2001. Calcareous soils in Miami-Dade County. Fact Sheet SL 183, a publication of the Soil and Water Science Department, Florida Cooperative Extension Service, Institute of Food and Agricultural Sciences, University of Florida. http://edis.ifas.ufl.edu/TR004

Li, Y.C., M. Zhang, and P.J. Stoffella. 2002. Utilization of fly ash and urban yard waste as soil amendments to improve soil fertility. Final Report No. TREC-LI02-06. Tropical Research and Education Center, University of Florida, Homestead, FL.

Wang, X., Y.C. Li, R. Muñoz-Carpena, P. Nkedi-Kizza and T. Olczyk. 2005. Effect of zeolitic soil amendment on phosphorus leaching in a sweet corn field. Soil Crop Sci. Soc. Florida Proc. 64:55-59. 